\title{
Relative Growth Rate and its Relationship to Compositional Changes of Nonstructural Carbohydrates in the Mesocarp of Developing Peach Fruits
}

\author{
E.W. Pavel and T.M. DeJong \\ Department of Pomology, University of California, Davis, CA 95616 \\ Additional index words. Prunus persica, carbon partitioning, growth analysis, fruit development
}

\begin{abstract}
Dry weights of whole fruit and of different fruit tissues, such as the mesocarp (with exocarp) and the endocarp (with seed), were accumulated on early ('Spring Lady'), midseason ('Flamecrest'), and late-maturing ('Cal Red') peach [ Prunus persica (L.) Batsch] cultivars during the 1988 growing season. Seasonal relative growth rate (RGR) patterns of whole fruit showed two distinct phases for 'Flamecrest' and 'Cal Red'; however, 'Spring Lady' did not exhibit two distinct RGR phases. The shift from phase I to phase II of the whole fruit RGR curve was related to an intersection of mesocarp and endocarp RGR curves, indicating a change of physiological sink activities in those fruit tissues in the later-maturing cultivars, but not in the early cultivar. Nonstructural carbohydrate compositional changes in concentration or content were similar in the three peach cultivars. Sucrose accounted for most of the seasonal increase in mesocarp nonstructural carbohydrate concentration. A sudden rise of sucrose was associated with the phase shift of the fruit RGR curves of the midseason and late-maturing cultivars, but not of the early maturing cultivar; however, in the early maturing cultivar, mesocarp compositional carbohydrate changes and, particularly, the sucrose increase, indicate that the physiological processes normally associated with the two phases exist in very early maturing fruit but are not associated distinctly with two separate RGR phases.
\end{abstract}

Peach fruit exhibit a double sigmoid growth pattern similar to that of other fruits (Coombe, 1960; Crane, 1948; Lilleland, 1930, 1932, 1933; Lilleland and Newsome, 1934; Tukey, 1933). Traditionally, the peach fruit double-sigmoid growth curve is divided into three stages: two rapid-growth stages are separated by a slowgrowth stage (Lilleland, 1932). Growth of the endocarp and individual seed compartments, such as nucellus, integuments, and endosperm, follow a sigmoid pattern, but the whole seed's growth pattern is double-sigmoid, because individual compartment growth is asynchronous. The seasonal growth pattern of the peach mesocarp and of the whole fruit is also double-sigmoid (Lott, 1942).

Two hypotheses have been proposed to explain regulation of the double-sigmoid growth curve in fruits: 1 ) control via assimilate competition among the seed, endocarp, and mesocarp; and 2) hormonal control of pericarp growth by the seed. Nitsch (1953) suggested that competition for assimilates between the endocarp and expanding mesocarp limits fruit expansion during stage two of the double-sigmoid growth curve. Similarly, Chalmers and van den Ende (1977) suggested a competition for assimilates between seed and pericarp throughout peach fruit development and correlated stage two of peach fruit growth with the embryo's period of rapid weight increase. However, competition for assimilates between endocarp and mesocarp does not occur in grapes (Vitis labrusca L.), because there is no endocarp lignification (Cawthon and Morris, 1982). Coombe's (1976) and Nitsch's (1953) suggestion that seed hormones regulate fruit growth seems unlikely, because early ripening peach varieties often abort embryos; however, the flesh develops to maturity as in other varieties (Ragland, 1934). Parthenocarpic peaches, figs (Ficus carica L.), and seedless grapes ( $V$. vinfera L.) (parthenocarpic or stenocarpic) also exhibit a double-sigmoid growth pattern during development (Coombe, 1960; Crane, 1948; Crane et al., 1961). Hormones (gibberellins,

Received for publication 7 May 1992. Accepted for publication 31 Oct. 1992. The cost of publishing this paper was defrayed in part by the payment of page charges. Under postal regulations, this paper therefore must be hereby marked advertisement solely to indicate this fact. auxins, cytokinins) produced by the seed in apples (Malus domestica Borkh.), peaches, figs, and grapes can be related to the growth of the seed (nucellus, integuments, endosperm, and embryo) itself, but there is no apparent relationship between seed hormones and regulation of seasonal fruit growth patterns (Crane et al., 1959; Farmahan and Pandey, 1976; Jackson, 1968; Luckwill, 1948). However, hormone activities in various fruit tissues seem to influence the growth of those same tissues (Jackson, 1968; Miller et al., 1987).

Although growth studies of various fruit species have taken many approaches, the mechanisms that control the cyclic growth patterns in fruit are not well understood. Recent studies have attempted to understand fruit growth by examining growth rates. The objective of growth analysis is to analyze plant growth on the basis of dry matter production as a function of duration and rate of growth (Hunt, 1982). DeJong and Goudriaan (1989) used relative growth rates (RGR) to study the cyclic growth patterns of two peach cultivars that mature at different times. The relationships between fruit RGRs and respiration rates were used to develop a peach fruit growth simulation model that calculated the daily fruit carbohydrate demands necessary to maintain fruit growth and respiration over the season. The model indicated that the peach fruit double-sigmoid growth pattern involves only two physiological phases of sink activity instead of the three usually recognized. During the first phase, fruit RGRs declined logarithmically with degree-day accumulation, and in the second phase, fruit RGRs remained constant. However, DeJong and Goudriaan (1989) did not attempt to relate the two phases of the fruit RGR curve to changes in peach fruit tissue growth patterns.

During development, fruit accumulate large amounts of carbohydrates. At harvest, soluble carbohydrates in peaches are $\approx 63 \%$ to $68 \%$ of dry matter (Buchloh and Neubeller, 1969; Lott, 1942). Recently, the seasonal composition patterns of nonstructural carbohydrates in peach mesocarp have been analyzed for various cultivars (Chapman and Horvat, 1990; Moriguchi et al., 1990a, 1990b). These studies either compared carbohydrate composition among cultivars (Chapman and Horvat, 1990; Moriguchi et al., 
1990a) or focussed on relationships between enzyme activities and sucrose and sorbitol metabolism (Moriguchi et al., 1990b). Miura et al. (1990) described the double-sigmoid growth pattern of developing strawberries (Fragaria $\times$ ananassa Duch.) with RGRs, exhibiting two phases, and analyzed the relative nonstructural carbohydrate composition of developing strawberries, but they did not relate growth analysis phases to composition. The goals of the present studies were to 1) validate the fruit RGR analysis techniques of DeJong and Goudriaan (1989) using three peach cultivars with contrasting fruit maturity dates, 2) relate whole fruit RGR patterns to the growth activity of the various fruit tissues during the season, and 3) determine associations between the two phases of peach RGR curves and the accumulation and composition of nonstructural carbohydrates in the peach mesocarp.

\section{Materials and Methods}

Fruit samples were taken from early ('Spring Lady'), midseason ('Flamecrest'), and late-maturing ('Cal Red') peach cultivars grown on Nemaguard rootstock at the Univ. of California's Kearney Agricultural Center, Parlier, during the 1988 growing season. Five-year-old trees of 'Spring Lady' and 'Cal Red' were trained to a high-density central leader system $(2.0 \times 4.0 \mathrm{~m})$. Twelve-yearold trees of 'Flamecrest' were trained to a low-density open vase system $(6.1 \times 6.1 \mathrm{~m})$. The study used commercial orchard cultural management practices, such as fertilization, pruning, thinning, and irrigation.

Seventy fruit per week and, later in the growing season, 60 fruit (excluding pedicels) were randomly sampled from 40 trees per cultivar from $\approx 4$ weeks after flowering until harvest. Fifty fruit were separated into groups of five, and each group was dried in an oven at 75 to $100 \mathrm{C}$ and weighed. Initially, 20 fruit and then, later in the growing season, 10 fruit were divided into groups of four and two, respectively, and separated into mesocarp (with exocarp) and endocarp (with seed). Each group was weighed, sliced, immediately frozen, and later freeze-dried. Fruit dry weight was determined after freeze-drying. The mesocarp tissue (including the exocarp) was ground to a fine powder for carbohydrate analysis.

Mean fruit dry weight accumulations over the season were used to calculate RGRs according to the method of Hunt (1982). Degree-day accumulations were integrated into the equations instead of daily time intervals, because fruit growth and development are dependent on temperature (Haun and Coston, 1983). Ambient air temperatures were monitored at a California Irrigation Management Information System weather station at the Kearney Agricultural Center, within $1 \mathrm{~km}$ of the study site. Degree-day accumulations were calculated from daily minimum and maximum temperatures by the single-sine method (Zalom et al., 1983) with lower and upper thresholds at 7 and 35C. The first and exponential phase of the RGR curve was fitted by regression analysis using the function $y=a \times x^{b}[\Leftrightarrow \ln y=b+\ln x+\ln a \Leftrightarrow$ $y=e^{b \times \ln x+\ln a}$, requiring a double-log data transformation. The RGR curve's second and constant phase was calculated as the mean of the RGRs during that phase according to the method of DeJong and Goudriaan (1989).

Fruit samples (100 mg, freeze-dried, ground powder) were extracted three times with $80 \%$ ethanol; after centrifugation, the supernatants were decanted and combined. Then, I $\mathrm{ml}$ of a mannitol-ethanol solution ( $1 \mathrm{mg}$ mannitol per $\mathrm{ml}$ of $80 \%$ ethanol) was added to each supernatant as an internal standard. The extracts were air-dried and stored at $-40 \mathrm{C}$. The residue was analyzed enzymatically for starch according to the method of Ettel (1981). The resulting glucose concentration was determined colorimetri- cally at a wavelength of $520 \mathrm{~nm}$ using a glucose diagnostic kit (Sigma Chemicals, St. Louis) and converted to starch by multiplying by 0.9 (Ettel, 1981).

For the determination of soluble carbohydrates, the dried supernatants were dissolved with $10 \mathrm{ml}$ of double-distilled water. The $\mathrm{pH}$ of the solution was adjusted to 7.0 with $0.2 \mathrm{M} \mathrm{KOH}$ or $0.2 \mathrm{M}$ $\mathrm{H}_{3} \mathrm{PO}_{4}$. To remove organic acids from the solution, $0.6 \mathrm{~g}$ of anion exchange resin (Amberlite IRA-68, Sigma Chemicals) was added, and the sample was shaken for $30 \mathrm{~min}$. The solution was then filtered and dried at 54C. The residue was dissolved with $5 \mathrm{ml}$ of double-distilled water and filtered with a $0.45-\mu \mathrm{m}$ membrane filter (Millipore Co., Bedford, Mass.).

A $20-\mu \mathrm{l}$ aliquot was injected into a high pressure liquid chromatograph (HPLC) (Isocratic Liquid Chromatograph, Model 330, Beckman Instruments, San Ramon, Calif.) equipped with a Beckman carbohydrate column ( $\mu$-Spherogel, $7.5 \times 300 \mathrm{~mm})$ and a refractive index detector (Model 156, Altex Scientific, Berkeley, Calif.) for sugar separation and quantification. The column was eluted with double-distilled water at $0.6 \mathrm{ml} \cdot \mathrm{min}^{-1}$ at $80 \mathrm{C}$. Standard solutions at $1 \mathrm{mg} \cdot \mathrm{ml}^{-1}$ of sucrose, glucose, fructose, mannitol (internal standard), and sorbitol (Sigma Chemicals) were used for calibration. Calculations of the peak areas were used to quantify the sugars expressed relative to the internal standard by means of a Model 3390A integrator (Hewlett Packard Co.. Avondale, Pa.) connected to the HPLC equipment.

\section{Results and Discussion}

Whole fruit dry weight accumulation in early ('Spring Lady'), midseason ('Flamecrest'), and late-maturing ('Cal Red') peach followed a double-sigmoid pattern over the season (Fig. 1), as reported by Lilleland (1932). The growth curves were not overlapping but separately staggered, depending on the cultivar and the time required to reach maturity. Final fruit dry weights increased from early to late-maturing cultivars. The cyclic growth of 'Flamecrest' and 'Cal Red' fruit could be divided into the three traditional stages. During the first and the third stage, the fruit grew in an exponential pattern and in stage two, the fruit growth was slow. In 'Spring Lady', stage two of the double-sigmoid growth curve could not be distinguished clearly, just as reported for other early cultivars of peach (DeJong et al., 1987; Lilleland, 1932) and cherry [Prunus avium (L.) L.] (Lilleland and Newsome, 1934).

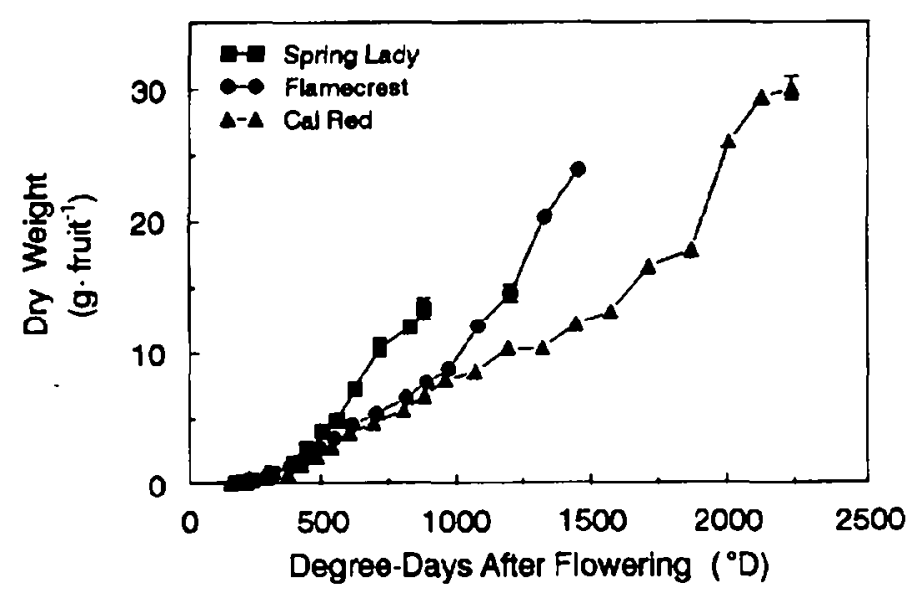

Fig. 1. Patterns of fruit dry weight accumulation of early ('Spring Lady'), midseason ('Flamecrest'), and late-maturing ('Cal Red') peach cultivars during the 1988 growing season (data points represent means \pm sE of 10 replicate fruit samples harvested on each date). 
Seasonal growth of individual peach fruit tissues showed that the mesocarp (with exocarp) exhibited a double-sigmoid pattern in the later-maturing cultivars (Figs. 3A and 4A), but 'Spring Lady' did not show distinctly the double-sigmoid growth curve (Fig. 2A). In contrast to the mesocarp, endocarp growth (with seed) followed a sigmoid pattern as reported by Lott (1942). The mesocarp, as the peach fruit's major component, apparently accounts for the whole fruit's double-sigmoid growth pattern.

Relative growth rates of whole fruit calculated with degreedays showed that dry matter accumulation in the later-maturing

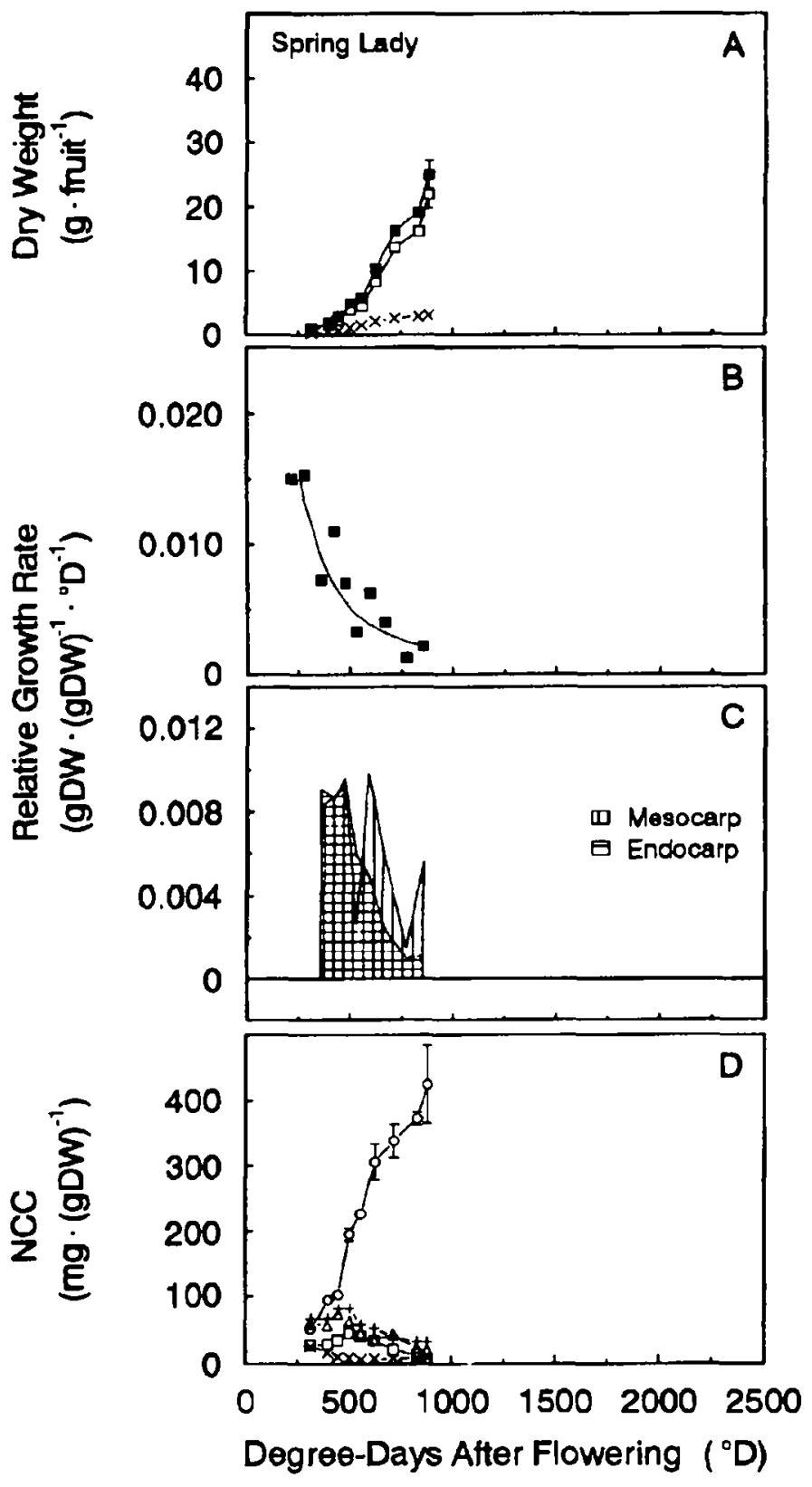

Fig. 2 (A) Seasonal patterns of dry weight accumulation of the whole fruit $(\square)$, mesocarp (כ), and endocarp ( $x$ ) of the early maturing 'Spring Lady' peach (data points represent means \pm st of five replicate fruit samples harvested on each date). (B) Seasonal relative growth rate patterns of the wholc fruit. The exponential function used to describe the decreasing phase of relative growth rates was $y=e$ $1.65 \ln x+501\left(r^{2}=0.78\right)$. (C) Seasonal relative growth rate patterns of the mesocarp (with exocarp) and endocarp (with seed). (D) Seasonal nonstructural carbohydrate concentrations (NCC) [ sucrose (O), glucose ( $\Delta$ ), fructose (+), sorbitol (ل), and starch $(x)$ ) of the mesocarp (data points represent means $\pm S E$ of five replicate fruit samples harvested on each date). peaches ('Flamecrest' and 'Cal Red') exhibited two distinct phases (Figs. 3B and 4B) consistent with the results of DeJong and Goudriaan (1989) and similar to work on grapes (Staudt et al., 1986). In the present study, actual fruit RGRs were plotted against degree-days after flowering, because the data could be fit better to a declining exponential function than a logarithmic function. Also, this relationship's units are easier to comprehend than the logarith-

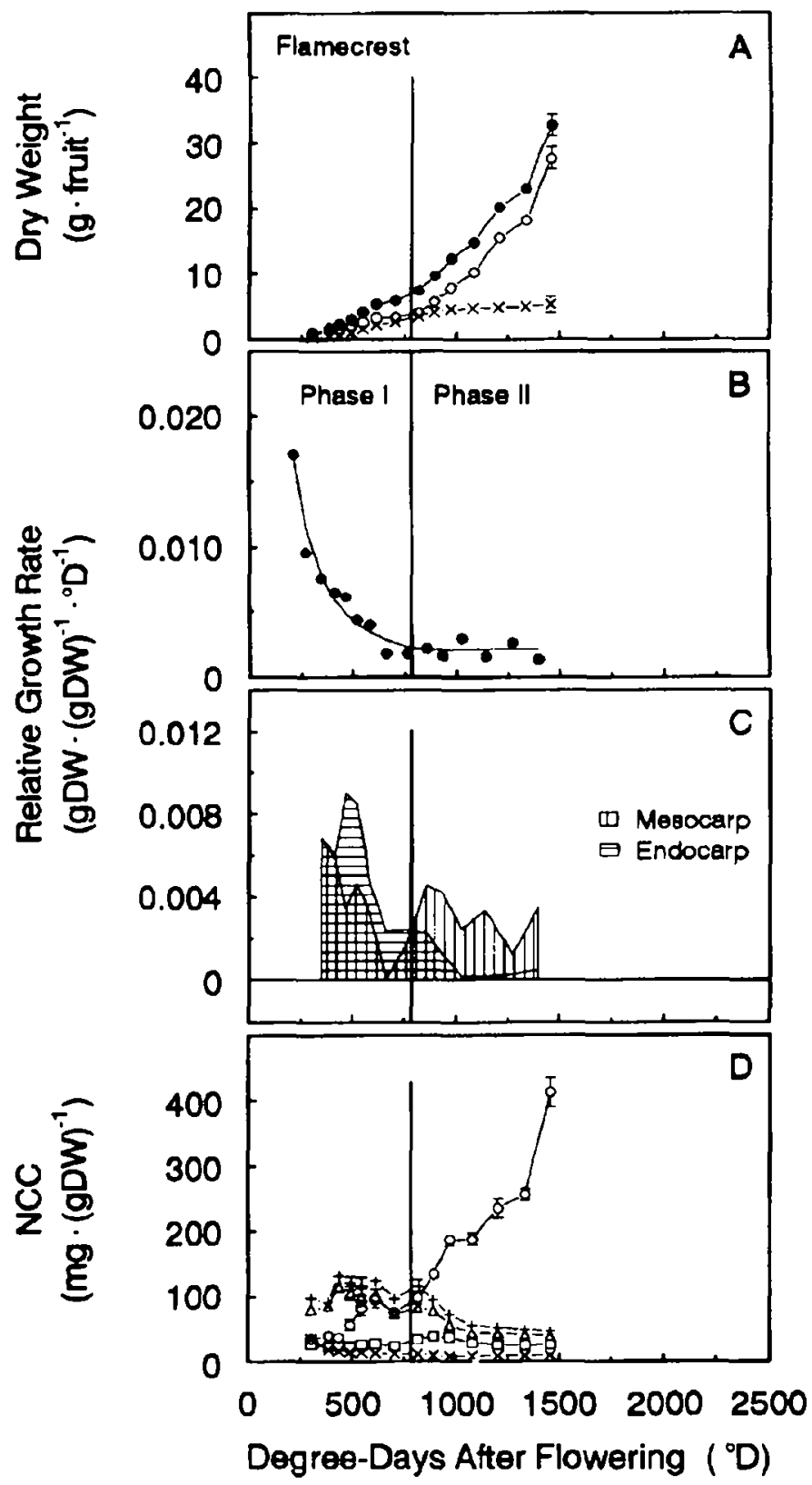

Fig. 3 (A) Seasonal patterns of dry weight accumulation of the whole fruit (O), mesocarp (O), and endocarp $(x)$ of the midscason-maturing 'Flamecrest' peach (data points represcnt means \pm st of five replicate fruit samples harvested on cach date). (B) Seasonal relative growth rate patterns of the whole fruit. The exponential function used to describe the decreasing phase of relative growth rates (phase $I$ ) was $y=e^{160 \ln x+4: 1}\left(r^{2}=0.92\right)$. The stable relative growth rate of phase II is represented by the mean relative growth rate during the last five points of the fruit growth curve $\left(\ddot{X}=1.99 \pm 0.94 \mathrm{mg} \mathrm{DW} \times(\mathrm{g} \mathrm{DW}){ }^{1} \times{ }^{\circ} \mathrm{D}^{-1}\right)$. The solid line indicates the approximate time when the phase shift of fruit relative growth rates occurs. (C) Seasonal relative growth rate patterns of the mesocarp (with exocarp) and endocarp (with seed). (D) Seasonal nonstructural carbohydrate concentrations (NCC) [sucrose (O), glucose $(\Delta)$, fructose $(+)$, sorbitol $(\square)$, and starch $(x)$ ] of the mesocarp (data points represent means \pm st of five replicate fruit samples harvested on each date). 
mic units. The RGR curve of the early peach, 'Spring Lady', began to level off near harvest, but two distinct phases were not clearly defined (Fig. 2B). In all three cultivars, the RGR decreased exponentially, indicating a negative relationship between fruit RGR and degree-day accumulation ('Spring Lady', $r^{2}=0.78$; 'Flamecrest', $r^{2}=0.92$; 'Cal Red', $\left.r^{2}=0.88\right)$. This is a 'Richards

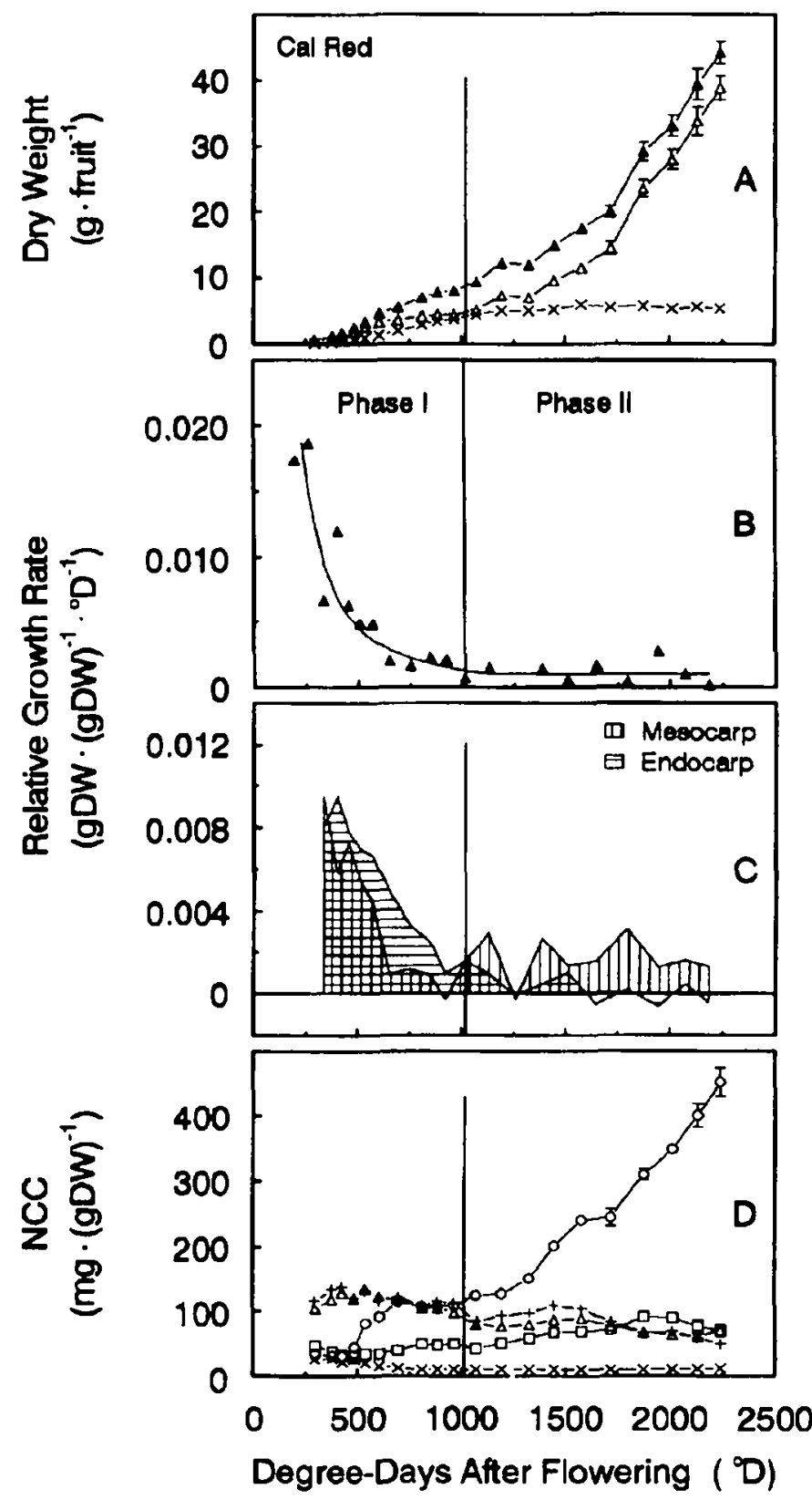

Fig. 4 (A) Seasonal patterns of dry weight accumulation of the whole fruit (A), mesocarp $(\Delta)$, and endocarp $(\times)$ of the late-maturing 'Cal Red' peach (data points represent means \pm se of five replicate fruit samples harvested on each date). (B) Seasonal relative growth rate patterns of the whole fruit. The exponential function used to describe the decreasing phase of relative growth rates (phase 1) was $y=$ $\mathrm{e}^{-1.791 \mathrm{ln} \times 5.76}\left(r^{2}=0.88\right)$. The stable relative growth rate of phase II is represented by the mean relative growth rate during the last nine points of the fruit growth curve $\left(\overline{\mathrm{X}}=1.06 \pm 1.71 \mathrm{mg} \mathrm{DW} \times(\mathrm{g} \mathrm{DW})^{\cdot 1} \times{ }^{\circ} \mathrm{D}^{-1}\right)$. The solid line indicates the approximate time when the phase shift of fruit relative growth rates occurs. (C) Seasonal relative growth rate patterns of the mesocarp (with exocarp) and endocarp (with seed). (D) Seasonal nonstructural carbohydrate concentrations (NCC) [sucrose $(O)$, glucose $(\Delta)$, fructose $(+)$, sorbitol $(\square)$, and starch $(x)$ ] of the mesocarp (data points represent means \pm SE of five replicate fruit samples harvested on each date). function' type of relationship and is used to describe sigmoid growth in biological studies (Hunt, 1982). The exponential functions used to describe the first phase of the RGR curves were $\mathrm{y}=$ $\mathrm{e}^{-1.65 \ln x+5.01}, \mathrm{y}=\mathrm{e}^{1.6 \mathrm{n} \ln \mathrm{n}+4.51}$, and $\mathrm{y}=\mathrm{e}^{-1.791 \mathrm{n} x+5.76}$ for 'Spring Lady', 'Flamecrest', and 'Cal Red', respectively. In the second phase, relative growth rates remained constant. The mean RGRs during the last five and nine points of the 'Flamecrest' and 'Cal Red' fruit growth-rate curves were $\mathrm{X}=1.99 \pm 0.94 \mathrm{mg} \mathrm{DW} \times(\mathrm{g} \mathrm{DW})^{-1} \times{ }^{\circ} \mathrm{D}^{-1}$ and $\mathrm{X}=1.06 \pm 1.71 \mathrm{mg} \mathrm{DW} \times(\mathrm{g} \mathrm{DW})^{-1} \times{ }^{\circ} \mathrm{D}^{-1}$, respectively, where $\mathrm{DW}$ $=$ dry weight and ${ }^{\circ} \mathrm{D}=$ degree-day. Shorter time to fruit maturity reduced the second-phase length for 'Flamecrest', but the mean RGR of 'Flamecrest' was higher than that of 'Cal Red'.

Seasonal relative growth rates of mesocarp (with exocarp) and endocarp (with seed) showed that in phase I, the endocarp had slightly higher RGRs than the mesocarp for the three cultivars (Figs. 2C, 3C, and 4C). Near the transition of phase I and phase II, RGRs of the mesocarp intersected the endocarp RGRs and generally remained higher until harvest. DeJong and Goudriaan (1989) relate the two phases of fruit RGRs to physiological sink activities based on dry matter accumulation. Thereby, the traditional stage two of the double-sigmoid growth curve represents the period when the shift between the two physiological phases of sink activity appears. With 'Flamecrest' and 'Cal Red', the shift from phase I to phase II of the whole fruit RGR curve (Fig. 2B, 3B. and 4B) appears to be associated with an intersection of RGR curves of mesocarp (with exocarp) and endocarp (with seed) (Fig. 2C, 3C, and $4 \mathrm{C}$ ), indicating a sink activity change in these fruit tissues. In phase I, the endocarp reached its maximum size, and during phase II fruit growth was dominated by weight increases of the mesocarp. Lott (1942) observed decreasing concentrations of soluble carbohydrates, starch, and hemicellulose in the peach endocarp during this period (phase II of the fruit RGR curve). 'Spring Lady', the earliest ripening peach, did not clearly exhibit two distinct RGR fruit phases. The 'Spring Lady' endocarp completed its growth shortly before harvest. The two physiological phases apparently overlapped because of the short time to fruit maturity in association with rapid developmental processes.

Seasonal nonstructural carbohydrate concentrations of peach mesocarp followed patterns similar to those of various peach cultivars as reported by Chapman and Horvat (1990) and Moriguchi et al. (1990a, 1990b). The seasonal concentration pattern and content of nonstructural carbohydrates were quite similar in the three peach cultivars (Figs. 2D, 3D, 4D, and 5); sucrose, glucose, and fructose were the main soluble carbohydrates. The sucrose concentration was the highest of the nonstructural carbohydrates and increased rapidly during the latter part of fruit development. The three peach cultivars differed with respect to the time of the sudden rise of sucrose concentrations. Glucose and fructose concentrations increased during early fruit growth and declined at the time sucrose was rapidly increasing. Glucose and fructose may have been converted to sucrose (Moriguchi et al., 1990b). Sorbitol, the main photosynthate translocated from leaves to fruits in the Rosaceae family, is metabolized to other sugars within fruits (Bieleski, 1969; De Villiers et al., 1974). The sorbitol concentration remained low and constant in peach fruit during the entire season, similar to starch. Sucrose dominance as the primary nonstructural carbohydrate in peach fruit is even clearer when expressed as content per fruit. It increased over the season in the same fashion as dry weight accumulated in the mesocarp in all three cultivars (Fig. 5). Contents of glucose, fructose, sorbitol, and starch were low and increased only slightly with fruit ripening.

Compositional changes of nonstructural carbohydrate concentrations in the peach mesocarp also appear to be related to the two 
phases of fruit RGRs in the later-maturing 'Flamecrest' and 'Cal Red' (Figs. 3 and 4). Sucrose concentrations increased rapidly when the fruit RGR curves shifted from phase I to phase II in the later-maturing peach cultivars. This relationship did not appear in 'Spring Lady' because the fruit RGR curve did not exhibit clearly two phases (Fig. 2). However, in 'Spring Lady', compositional changes in mesocarp carbohydrates, particularly the sucrose increase, indicate that two physiological phases similar to the other cultivars apparently exist, although fruit RGRs do not show them. Strawberries also accumulate high amounts of sucrose when fruit RGRs start to level off after an initial decrease in young fruits (Miura et al., 1990). However, Miura et al. (1990) did not relate the seasonal pattern of fruit RGRs to the rapidly increasing sucrose concentrations in strawberry tissue.

The results of this research indicate that the two-phase RGR model proposed by DeJong and Goudriaan (1989) can be adapted to describe whole fruit growth of other peach cultivars. Individual fruit tissue growth analysis indicates that the RGR model's shape depends on the juxtapostion in time of the fruit's two major growth components (i.e., the mesocarp and endocarp). Most cultivar differences in the whole fruit RGR patterns are the result of changes in timing and magnitude of mesocarp growth rather than endocarp growth. Therefore, for developmental and physiological studies, peach fruit growth should probably be studied as if peaches were composed of two separate but interdependent or-

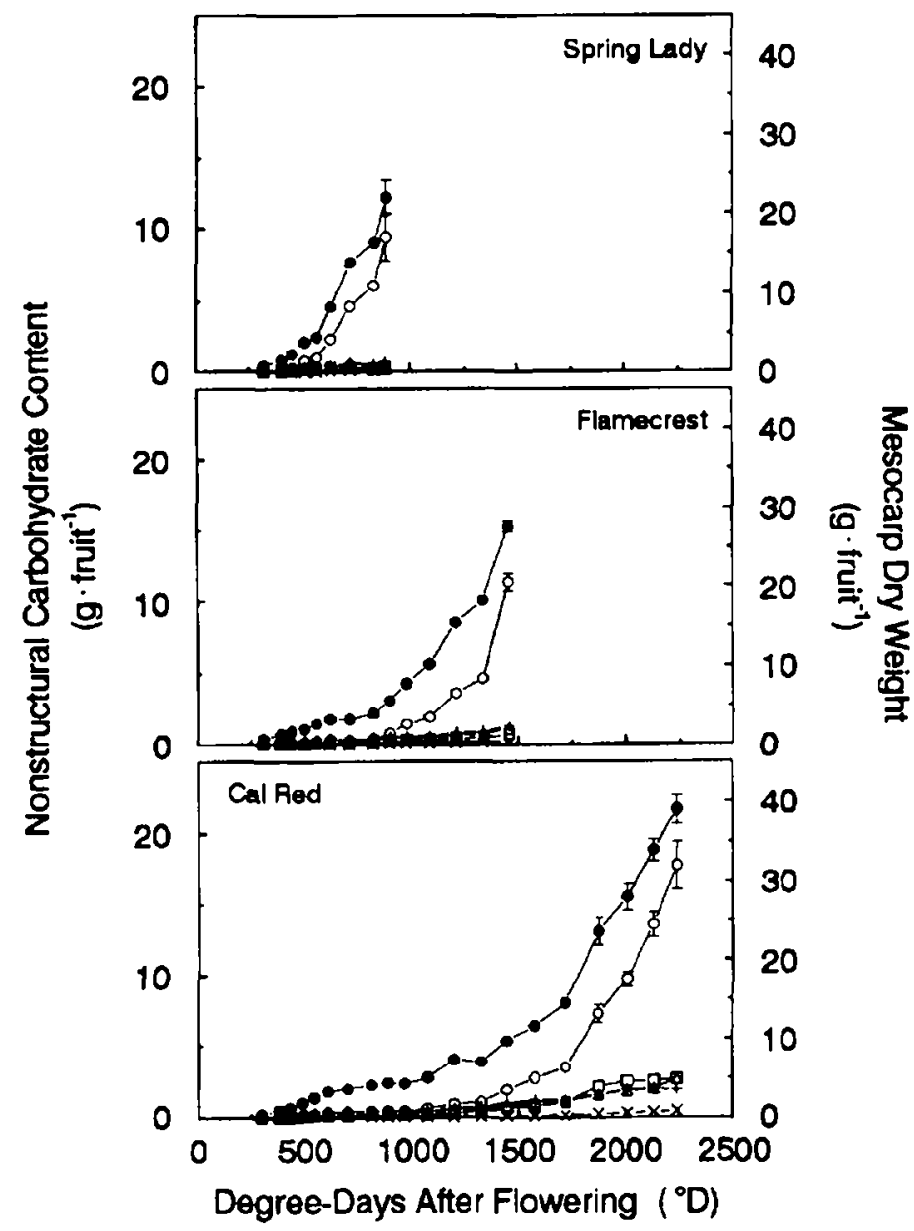

Fig. 5. Seasonal dry weight accumulation (O) and nonstructural carbohydrate content [sucrose $(O)$, glucose $(\Delta)$, fructose $(+)$, sorbitol $(\square)$, and starch $(\times)$ ] per fruit of peach mesocarp in early ('Spring Lady'), midseason ('Flamecrest'), and late-maturing ('Cal Red') peach cultivars (data points represent means \pm sE of five replicate fruit samples harvested on each date). gans. From this perspective, there appears to be little validity to early hypotheses that seed or endocarp development regulate the timing of mesocarp growth.

The data for mesocarp carbohydrates clearly indicate that changes in their metabolism are associated with mesocarp growth. Researchers working on developmental gene regulation have postulated that each plant organ has an organ-specific set of genetic codes for regulating that organ's development (Okamuro and Goldberg, 1989). Perhaps the changes in mesocarp carbohydrate metabolism are an expression of this type of organ specific developmental gene regulation and this, in turn, determines the mesocarp growth pattern.

\section{Literature Cited}

Bieleski, R.L. 1969. Accumulation and translocation of sorbitol in apple phloem. Austral. J. Biol. Sci. 22:611-620.

Buchloh, G. and J. Neubeller. 1969. Zur qualitativen und quantitativen Bestimmung von Zuckern und Zuckeralkoholen in einigen Obstfrüchten mittels Gaschromatographic. Erwerbsobstbau 11:22-27.

Cawthon, D.L. and J.R. Morris. 1982. Relationship of seed number and maturity to berry development, fruit maturation, hormonal changes, and uneven ripening of 'Concord' (Vitis labrusca L.) grapes. J. Amer. Soc. Hort. Sci. 107:1097-1104.

Chalmers, D.J. and B. van den Ende. 1977. The relation between seed and fruit development in the peach ( Prunus persica L.). Ann. Bot. 41:707714.

Chapman, G.W. and R.J. Horvat. 1990. Changes in nonvolatile acids, sugars, pectin, and sugar composition of pectin during peach (cv. Monroe) maturation. J. Agr. Food Chem. 38:383-387.

Coombe, B.C. 1960. Relationship of growth and development to changes in sugars, auxins and gibberellins in fruit of seeded and seedless varieties of Vitis vinifera. Plant Physiol. 35:241-250.

Coombe, B.G. 1976. The development of fleshy fruits. Annu. Rev. Plant Physiol. 27:507-528.

Crane, J.C. 1948. Fruit growth of four fig varieties as measured by diameter and fresh weight. Proc. Amer. Soc. Hort. Sci. 52:237-244.

Crane, J.C., M.V. Bradley, and L.C. Luckwill. 1959. Auxins in parthenocarpic and non-parthenocarpic figs. J. Hort. Sci. 34:142-153.

Crane, J.C., C.A. Rebeiz, and R.C. Campbell. 1961. Gibberellin-induced parthenocarpy in the J.H. Hale peach and the probable cause of "button" production. Proc. Amer. Soc. Hort. Sci. 78:111-118.

DeJong, T.M., J.F. Doyle, and K.R. Day. 1987. Seasonal patterns of reproductive and vegetative sink activity in early and late maturing peach (Prunus persica) cultivars. Physiol. Plant. 71:83-88.

DeJong, T.M. and J. Goudriaan. 1989. Modeling peach fruit growth and carbohydrate requirements: Re-evaluation of the double-sigmoid growth pattern. J. Amer. Soc. Hort. Sci. 114:800-804.

De Villiers, O.T., J.T. Meynhardt, and J.A. de Bruyn. 1974. Translocation of sorbitol and sugars in Santa Rosa plums. Agroplantae 6:33-36.

Ettel, W. 1981. Eine neue enzymatische Stärkebestimmung für Lebensmittel. Alimenta 20:7-11.

Farmahan, H.L. and R.M. Pandey. 1976. Hormonal regulation of the lag phase in seeded and seedless grapes (Vitis vinifera L.). Vitis 15:227235.

Haun, J.R. and D.C. Coston 1983. Relationship of daily growth and development of peach leaves and fruit to environmental factors. J. Amer. Soc. Hort. Sci. 108:666-671.

Hunt, R. 1982. Plant growth curves. E. Arnold, London.

Jackson, D.I. 1968. Gibberellin and the growth of peach and apricot fruits. Austral. J. Biol. Sci. 21:209-215.

Lilleland, O. 1930. Growth study of the apricot fruit. Proc. Amer. Soc. Hort. Sci. 27:237-245.

Lilleland, O. 1932. Growth study of peach fruits. Proc. Amer. Soc. Hort. Sci. 29:8-12.

Lilleland, O. 1933. Growth study of the plum fruit. I. The growth and changes in chemical composition of the Climax plum. Proc. Amer. Soc. Hort. Sci. 30:203-208. 
Lilleland, O. and L. Newsome. 1934. A growth study of the cherry fruit. Proc. Amer. Soc. Hort. Sci. 32:291-299.

Lott, R.V. 1942. Effect of nitrate soda on development of the Halchaven peach. Univ. Illinois Agr. Expt. Sta. Bul. 493:323-384.

Luckwill, L.C. 1948. The hormone content of the seed in relation to endosperm development and fruit drop in apple. J. Hort. Sci. 24:32-44.

Miller, A.N., C.S. Walsh, and J.D. Cohen, 1987. Measurement of indole3-acetic acid in peach fruits (Prunus persica L. Batsch cv Redhaven) during development. Plant Physiol. 84:491-494.

Miura, H., S. Imada, and S. Yabuuchi. 1990. Double sigmoid growth curve of strawberry fruit. J. Japan Soc. Hort. Sci. 59:527-531.

Moriguchi, T., Y. Ishizawa, and T. Sanada. 1990a. Differences in sugar composition in Prunus persica fruit and the classification by the principal component analysis. J. Japan Soc. Hort. Sci. 59:307-312.

Moriguchi, T.. T. Sanada. and S. Yamaki. 1990b. Seasonal fluctuations of some enzymes relating to sucrose and sorbitol metabolism in peach fruit.
J. Amer. Soc. Hort. Sci. 115:278-281.

Nitsch, J.P. 1953. The physiology of fruit growth. Annu. Rev. Plant Physiol. 4:199-236.

Okamuro, J.K. and R.B. Goldberg. 1989. Regulation of plant gene expression: General principles, p. 1-82. In: A. Marcus (ed.). The biochemistry of plants. vol. 15, Molecular Biology. Academic, San Diego. Ragland, C.H. 1934. The development of the peach fruit, with special reference to split-pit and gumming. Proc. Amer. Soc. Hort. Sci. 31:1-21. Staudt, G., W. Schneider, and J. Leidel. 1986. Phases of berry growth in Vitis vinifera. Ann. Bot. 58:789-800.

Tukey, H.B. 1933. Growth of the peach embryo in relation to growth of fruit and season of ripening. Proc. Amer. Soc. Hort. Sci. 30:209-218.

Zalom, F.G., P.B. Goodell, L.T. Wilson, W.W. Barnett, and W.J. Bentley. 1983. Degree-days: The calculation and use of heat units in pest management. Div. Agr. Natural Resources. Univ. California, Lflt. 21373:1-10. 